\title{
Embedded Flower Pollination Evolutionary Programming Based Technique for Voltage Stability Enhancement with Distributed Generation Installation
} \\ Nik Nuruljannah Mansor ${ }^{1}$, Sharifah Azwa Shaaya ${ }^{2}$, Ismail Musirin ${ }^{3}$, Naeem S Hannoon ${ }^{4}$, Zellagui \\ Mohamed $^{5}$, Mohamad Khairuzzaman Mohamad Zamani ${ }^{6}$ \\ 1,3,4,6 Faculty of Electrical Engineering, Universiti Teknologi MARA, Shah Alam, Selangor, Malaysia, \\ nikjannah.mansor@yahoo.com, ismailbm@salam.uitm.edu.my, hannoon.naeem@gmail.com, \\ mohd_khairuzzaman@yahoo.com \\ ${ }^{2}$ Department of Electrical Engineering, Universiti Tenaga Nasional, Kajang, Selangor, Malaysia, \\ shazwa@uniten.edu.my \\ ${ }^{5}$ Department of Electrical Engineering, École de Technologie Supérieurs (ÉTS),University of Québec, Montréal, \\ Québec, Canada, m.zellagui@ymail.com
}

\begin{abstract}
This paper presents the embedded flower pollination evolutionary programming-based technique for voltage stability enhancement with distributed generation installation. In this study, a new technique is developed which combines the element of flower pollination into the general evolutionary programming algorithm. The aim is to enhance the voltage stability in power system with the presence of distributed generation. The proposed technique was validated using the IEEE 33-Bus Distribution System. Results obtained from the study revealed that the proposed technique is better than EP in terms of optimizing the sizing of DG and location.
\end{abstract}

Key words : Embedded, Distributed, Pollination, Voltage

\section{INTRODUCTION}

Increasing loading condition in a power system network had driven the power system operating close to its stressed condition leading to unfortunate power contingencies occurrences such as power system collapse. There are several aspects that may lead into a power system collapse. The impact of voltage stability in a power system stability can be taken into consideration as it is very crucial to prevent the power system from voltage instability while ensuring maximum loadability could be deliver to user [1]. For this study purposes, in order to optimize the maximum voltage stability value, distributed generation was injected at appropriate location with certain power sizing (MW) in order to boost that power system efficiency [2]. Voltage stability studies was becoming crucial as power system had to operate near stability constraint in order to save the investment cost. While the maximum voltage stability value is calculated line by line and any out of range value could become major problem in power system stability. The main purpose of distributed generation installation serves as maintaining acceptable voltage range during normal condition and disturbance occurrence [3]. Voltage instability could occur in conjugate to contingencies occurrence beforehand thus making it crucial to have the overall voltage stability monitored in a power system [1]. In accordance with the IEEE power system committee standard, voltage stability is also defined as the ability of power system in maintaining the stability range of the voltage when load admittance is increasing in the power system consulting in increasing the overall loading condition of power system thus resulting in making the power and voltage both controllable [4].

This paper presents the embedded flower pollination evolutionary programming-based technique for voltage stability enhancement with distributed generation installation. By using the combination technique of evolutionary programming and flower pollination algorithm the maximum FVSI value during maximum loading condition was evaluated and the most stable index value after placement with suitable DG sizing was obtained. Validation was conducted on the IEEE 33-Bus Radial Distribution System (RDS) and results revealed that the proposed technique outperformed EP in terms of voltage stability enhancement. Larger test system can be the future test system using the similar proposed technique.

\section{METHODOLOGY}

This section presents the research methodology of the study including the literature study regarding the general power system and the computational methods. There are two types of voltage stability in small disturbance voltage stability analysis, which are known as the static voltage stability and dynamic voltage stability however in this project, static voltage stability was chosen as it contained a load flow equation for simulation purposes [5]. In calculating the voltage stability of power system, fast voltage stability index (FVSI) method was proposed by Musirin et. al [6]. The voltage stability index margin ranging from zero until one. The FVSI implies a stable system at its minimum value, close 
to zero; while its value close to 1.0 implies an unstable condition. FVSI can be mathematically expressed as in (1). While formulating the expression, several assumptions mentioned in (2) are taken into consideration.

$$
F V S I=\frac{4 Z^{2} Q_{r}}{V_{s}^{2} X}
$$

$$
\sin \delta \approx 0, \cos \delta \approx 1, R \sin \delta \approx 0, X \cos \delta \approx X
$$

\subsection{Distributed Generation}

Distributed generation is also known as on-site generation / dispersed generation / embedded generation or decentralized generation [7]. DG main purpose was to solve power system quality problem by improving system efficiency, eliminate high cost peak load voltage profile, reducing system losses, system continuity and reliability by contributing active and passive power into the system [8]. However, some studies also shown the opposite scenario which indicate that the installation of DG could increase problem with the power quality in power network [9]. Systematic planning strategies are important in allocating DG unit so power system will not be facing further increase of system losses which include high network capital and operating cost aside from decreasing the network losses and increasing the power quality supply [3][10]. There are several methods and formulation involved in finding the most optimum placement and sizing of the distributed generation including analytical tools and also heuristic optimization methods. In finding the most suitable location for DG placement, some of the most common strategies are by assessing the power losses parameter in system or based on the voltage bus index stability [11] which may be achieved by using evolutionary computational technique yet for the purpose of analysis in this paper, randomize location and sizing of DG was done and overall voltage stability value was calculated using each injected power by this DG which eventually resulted in the lowest possibly voltage stability value.

In determining the best location and sizing for DG considering the maximum loading condition, optimum location and sizing variables were randomized and total maximum voltage stability index (FVSI) was calculated from each randomized value which in eventually the lowest of the voltage stability value was considered in obtaining the optimal placement and sizing of DG.

In this study, supposedly renewable energy sources were used as distributed generation in the system analysis. For that assumption made for all four DGs in the analysis were used in this study was solar thermal type. Since the emerging of solar farm technologies around the globe student used this type of DG in the study with the power range for these solar farms were set to 50MW for all four types of DGs.

\subsection{Computational Technique}

In enhancing the voltage stability margin, computational method was introduced in calculating the lowest possible maximum voltage stability index (FVSI) in conjugate to the optimal placement and sizing of installed DG. In previous studies, several optimization techniques have been implemented to solve optimal DG allocation problem such as Bee Colony Optimization (BCO) [12] and Ant Colony Search Optimization (ACO) [13]. In this study, the main optimization technique used is embedded evolutionary flower pollination algorithm, that introduces the combination of evolutionary programming and flower pollination algorithm for optimizing the FVSI. Comparison between the embedded technique and existing evolutionary programming-based technique was made to justify the most effective technique used between the two methods.

\subsubsection{Evolutionary Programming}

Evolutionary Programming (EP) is a population-based metaheuristic optimization search technique that is a part of Evolutionary Computation technique. This technique uses the optimization process is the development or adjusting any fitness to improve it using a mathematical procedure that will search for minimum and most optimum value. It was commonly used to solve problem involved complicated constraint and design parameter [14]. Evolutionary programming is a more robust approached stochastic optimization technique. This technique use a global multiagent minimization method [15] in finding the optimal solution using initial random guess or by creating numbers of population over the numbers of iterations which eventually set by the limit margin of proposed optimized criterion [16].

Initialization process where the population for the variable of placement and sizing of the installed DGs was generated randomly before running the load flow for the 33-Bus system and maximum loading condition value was injected into the system to obtain the maximum FVSI value. For fitness 1, each data for location and sizing were obtained from the initialization process and the value for the FVSI should be the same. During mutation process of the 20 new individuals, offspring, which is the latest variable value were generated from the parent, fitness 1 value using these equations (3) and (4):

$$
\begin{gathered}
X_{i+m, j}=X_{i, j}+N\left(0, \sigma_{i, j}^{2}\right) \\
\sigma_{i, j}^{2}=\beta\left(X_{j, \max }-X_{j, \min }\right)\left(\frac{f_{i}}{f_{\max }}\right)
\end{gathered}
$$

where,

$X_{i+m}=$ offspring

$X_{i, j}=$ parent

$N\left(\mu, \sigma^{2}\right)=$ Gaussian random variable with mean $\mu$ and variance $\sigma^{2}$

$\beta=$ mutation scale. $0<\beta<1$ which can be adjusted for more accurate result

$X_{\text {jmax }}=$ maximum value of random number for each variable

$X_{j \min }=$ minimum value of random number for each variable

$f_{i}=$ fitness for the $i^{\text {th }}$ of randomize number

$f_{\text {max }}=$ maximum value of overall fitness 
Mutated offsprings and parents were then combined and gone through selection process depending on the smallest maximum voltage stability value which 20 best value from the selection process was chosen depending on the ascending voltage stability value.

For this project the convergence criterion of the voltage stability index was set to be less than 0.00001 so the accuracy of result was more precise.

\subsubsection{Flower Pollination Algorithm (FPA)}

Flower pollination algorithm and evolutionary programming both are known as the stochastic technique. The rules for formulated the flower pollination is a modern optimization, the evolutionary technique based on the characteristic of flower pollination mechanism was inspired by nature that effectively deal with continuous combination problem [17][18].

In this technique, it is inspired from the flower pollination concept and related to reproduction via pollination which involved the transfer of pollen, the following are the characteristic of flower pollination algorithm characteristic [19][20]:

- Cross pollination and biotic is a global process of pollination which the pollinators carry the pollen and was performed by Levy flights

- Self-pollination and abiotic are the local pollination technique.

- Flower constancy is the reproduction probability that proportional to similarities of two flowers involved.

- In terms of controlling between the local and global pollination, the randomized switch probability was used which is $[0,1]$.

Flower pollination concept and equation involved was embedded into the evolutionary programming solution in order to optimize the overall result. This project however also includes the concept and formulation of the local and global pollination in generating converged output solution and the probability switch value used classified solution into either the global or local pollination was 0.8. Maximum and minimum set point for each parameter was also set so the pollinated value will not search off the range limit. Equations used in the analysis study are listed as follow:

As for global pollination, flower pollen is carried by pollinators which may travel over long distance and this rule is represented mathematically using (5) and (6):

$$
X_{i}^{t+1}=X_{i}^{t}+L(\lambda)\left(X_{i}^{t}-B\right)
$$

$$
X_{i}^{t+1}=i^{t h} \text { pollen at } t^{\text {th }} \text { iteration. }
$$

$B=$ current iteration best solution

$L(\lambda)=$ parameter correspond to the strength of pollination or the step size

Levy flight also can be used to imitate this characteristic, from that we use the Levy distribution formulation which used in any flower pollination technique:

$$
L \square \frac{\lambda \Gamma(\lambda) \sin \left(\frac{\pi \lambda}{2}\right)}{\pi} \frac{1}{S^{1+\lambda}},\left(S \square S_{0}>0\right)
$$

Local pollination process can be modelled as expressed in (7).

$$
X_{i}^{t+1}=X_{i}^{t}+U\left(X_{j}^{t}-X_{k}^{t}\right)
$$

\subsubsection{Summary}

Several studies had shown combination artificial intelligent technique of flower pollination algorithm with other artificial intelligent techniques [21][22] which eventually each will have different types of objective function and constraints so does the overall performance of these combination techniques [23] for this paper, flower pollination concept and formulation used was embedded into evolutionary technique and the overall performance was recorded, evaluate and compared with the evolutionary programming technique.

Figure 1 shows the flow graph of overall step involved by using the Evolutionary programming solution in optimizing the overall voltage stability for the IEEE 33 bus system. The proposed embedded flower pollination evolutionary programming is shown in Figure 2.

Flower pollination algorithm concept and equations are embedded into the original algorithm of the evolutionary programming technique as seen in Figure 1. This embedded technique used the global and local pollination formula in generating the new solution which is fitness 3 from data fitness 1. The data gathered from fitness 1, fitness 2 and fitness 3 were then combined and the best optimization result among the overall data will be displayed.

Figure 3 shows the single line diagram of a 33-bus distribution power system. This system has 32 connecting line between the buses with single slack bus and 32 load bus. Maximum loading condition was added at bus 10 which slightly further from the power source and located in centre of the distributed system and any insignificant instability could possibly affect the overall power system more than the one located further from generating source supply.

where; 


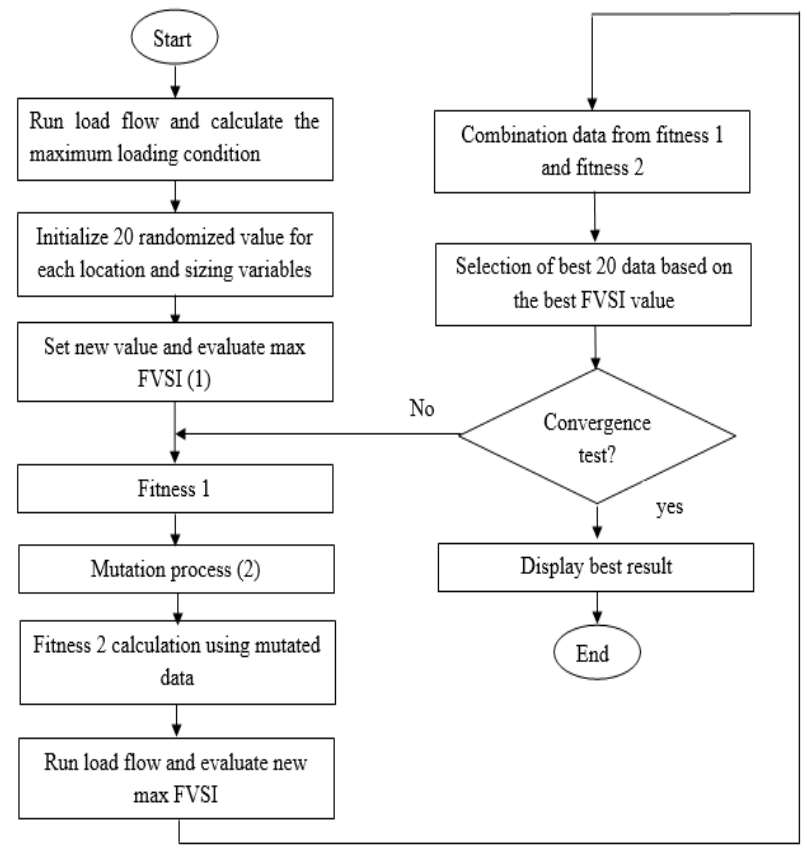

Figure 1: Flowchart of EP

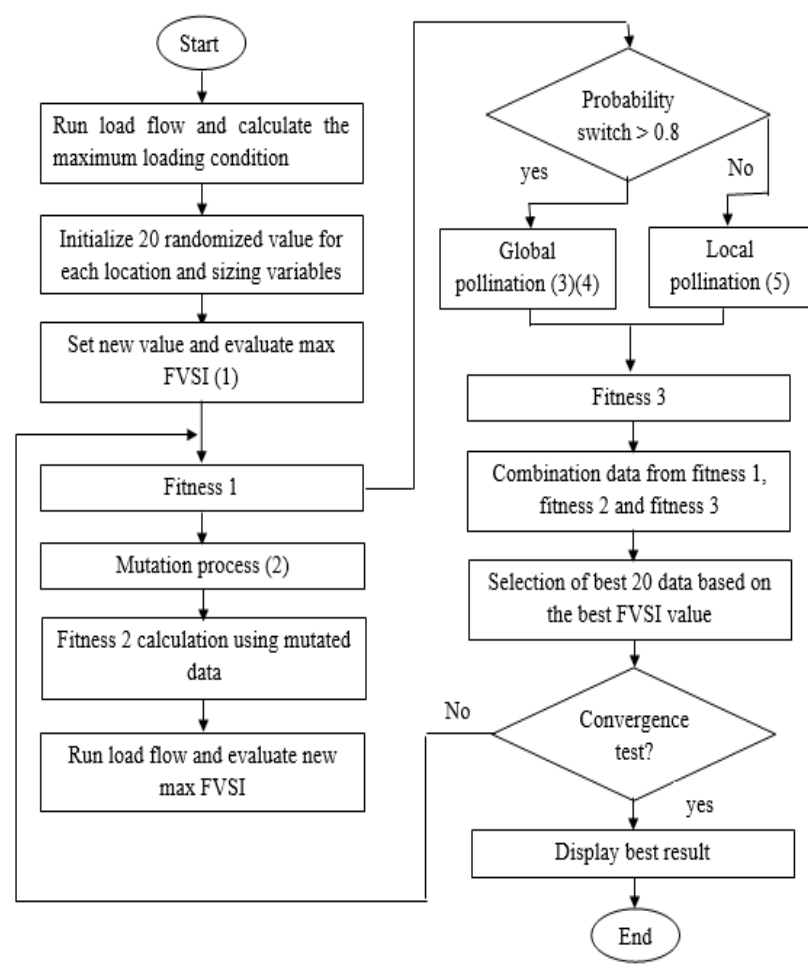

Figure 2: Flowchart of the proposed optimization technique

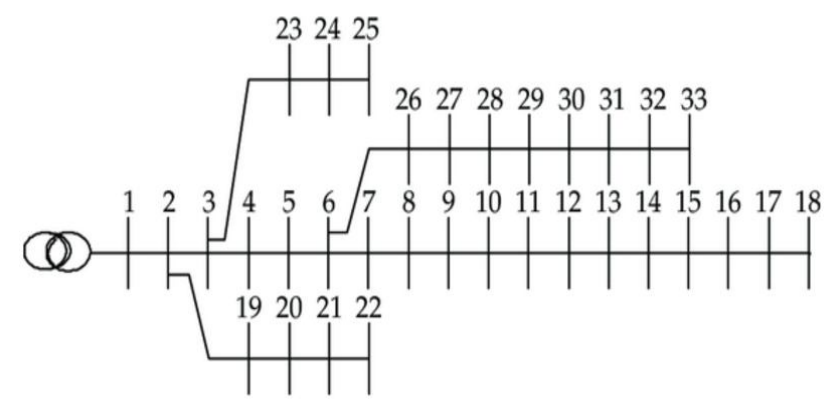

Figure 3: Single-Line Diagram of IEEE 33-Bus RDS

\section{RESULT AND DISCUSSION}

Evaluating the overall voltage stability after DG installation was conducted, R2017a version MATLAB software was used to simulate the IEEE 33-bus RDS. Finalized simulation resulting in optimal placement and sizing of DG with better voltage stability value was recorded and compared which fulfil the objective of the project analysis.

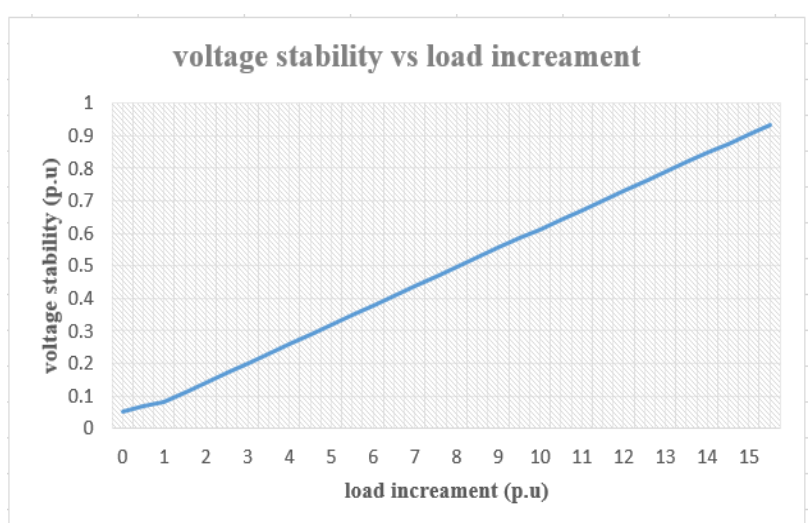

Figure 4: voltage stability vs load increament

Figure 4 presents the increment of FVSI value as the load was increased at bus 10 . Voltage collapse could occur when the FVSI value had reach peak value of voltage collapse point at 1 . The maximum value of load increament before the voltage collapse in the system takes place was recorded at 15.5 p.u. Maximum voltage stability point value was recorded at 0.9161 p.u. before voltage collapse. In order to find the best optimized voltage stability, reduction of initial voltage stability value towards 0 must be done. Maximum loading condition was used throughout the analysis prior to monitoring the difference in voltage stability value before and after distributed generation was installed. 


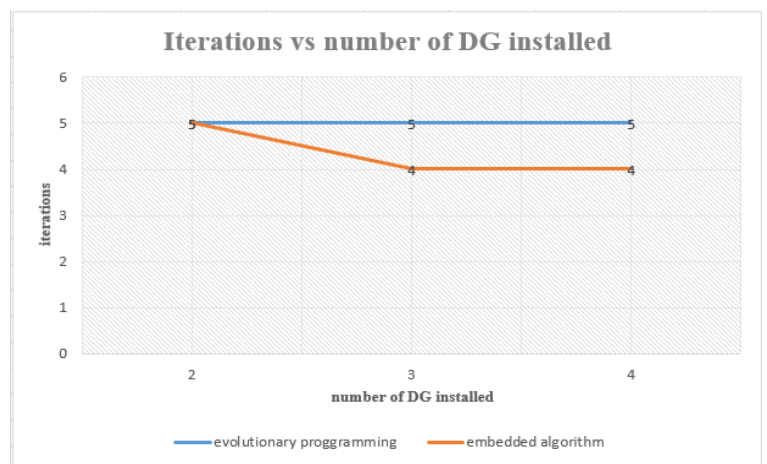

Figure 5: Comparison graph on the number of iteration with different computational method used

Embedded evolutionary flower pollination algorithm method was better in term of number of iteration compared to evolutionary programming as the search in the embedded method, the parent were mutated and pollinated before the three set of data were combined to get a better convergence rate. For the embedded evolutionary pollination algorithm, the iteration rate eventually become smaller with higher number of DG installed as the search area was bigger so smallest maximum FVSI value could be calculated was easier.

Tabulated data in Table 1 was collected using evolutionary programming method with installed distributed generation power value ranging from 0MW until 50MW. Increasing number of DG installed did show a decreasing value of maximum FVSI which eventually improve the voltage stability of power system however the computational time for bigger number of DG installed take much longer than smaller number. However, more number on DG installation might affect the overall system performance so limitation on DG added was up to $4 \mathrm{DG}$ only for this analysis. With initial FVSI of 0.9161 it gradually lowered with the installation of DG units which varied from $0.8857,0.8779$ and 0.8722 p.u showing that the distributed system become more stable with more DG unit installation.

Table 1: Comparison of number of DG installed with the value of maximum FVSI calculated using EP

\begin{tabular}{ccccc}
\hline $\begin{array}{c}\text { Number } \\
\text { of DG } \\
\text { installed }\end{array}$ & $\begin{array}{c}\text { DG location } \\
\text { (bus number) }\end{array}$ & $\begin{array}{c}\text { DG sizing } \\
\text { (MW) }\end{array}$ & $\begin{array}{c}\text { Max } \\
\text { FVSI } \\
\text { (p.u) }\end{array}$ & $\begin{array}{c}\text { Elapsed } \\
\text { time (s) }\end{array}$ \\
\hline 2 & 20 & 24.4247 & 0.8857 & 12.9062 \\
\hline & 10 & 23.2005 & & \\
3 & 26 & 0.7934 & & 13.3438 \\
& 28 & 34.4228 & 0.8779 & \\
\hline & 6 & 43.4142 & & \\
4 & 26 & 34.4228 & & \\
& 28 & 43.4142 & 0.8722 & 16.5078 \\
& 6 & 31.4772 & & \\
\hline
\end{tabular}

Table 2 tabulates data gathered from embedded evolutionary programming method in calculating the optimal placement and sizing of the in conjugate with the optimized voltage stability index, FVSI value. Comparing to the value gathered from table 1 , the data for two DG placement and three DG placement shown a quite differ value as the embedded method was quite unstable as different set of value could be obtained in the first two computation process. Based on table 1 the DG placement were quite similar for three and four DG placement however by using this technique the different and most optimized DG placement could be found for two and three DG placement. This method however did show different value for each computation, so the most frequent results were used in tabulating the finalized data. Yet this method shown almost the same value, iterations and computational time for four DG installed.

Table 2: Comparison of number of DG installed using embedded evolutionary programming method

\begin{tabular}{ccccc}
\hline $\begin{array}{c}\text { Number } \\
\text { of DG } \\
\text { installed }\end{array}$ & $\begin{array}{c}\text { DG location } \\
\text { (bus number) }\end{array}$ & $\begin{array}{c}\text { DG sizing } \\
\text { (MW) }\end{array}$ & $\begin{array}{c}\text { Max } \\
\text { FVSI } \\
\text { (p.u) }\end{array}$ & $\begin{array}{c}\text { Elapsed } \\
\text { time (s) }\end{array}$ \\
\hline \multirow{2}{*}{2} & 30 & 40.6007 & & \\
\hline & 28 & 40.2514 & 0.8849 & 15.8584 \\
\hline 3 & 18 & 25.9029 & & \\
& 12 & 21.5411 & 0.8707 & 14.6332 \\
& 20 & 12.9408 & & \\
\hline & 26 & 34.4228 & & \\
& 28 & 43.4142 & 0.8722 & 15.8510 \\
& 6 & 31.4772 & & \\
\hline
\end{tabular}

Based on Figure 6, the maximum FVSI value is better using the embedded evolutionary flower pollination algorithm as compared to the evolutionary programming itself. The maximum value was slightly lower for two DG installed however it shown quite differ during three DG installed into the power network. The embedded evolutionary flower pollination algorithm however had quite unstable result for the first time running as compared to evolutionary technique which had the same result for each computation. However, with greater number of DG installed the system had better stability on the convergence rate.

Comparison on the computational time taken between each artificial intelligence methods to complete each load flow calculation was also recorded as in Figure 7. The time taken for EP had a constant increasing rate comparing to the embedded evolutionary flower pollination algorithm. The embedded method however shown quite unusual value and quite unstable for time evaluation as each time the load flow was calculated the time might differ so the most frequent and similar in time computation were recorded in the result data. The time taken for embedded evolutionary programming did show a higher value as this method had more lines to read during running the load flow compared to the EP. 
FVSI value vs number of DG installed

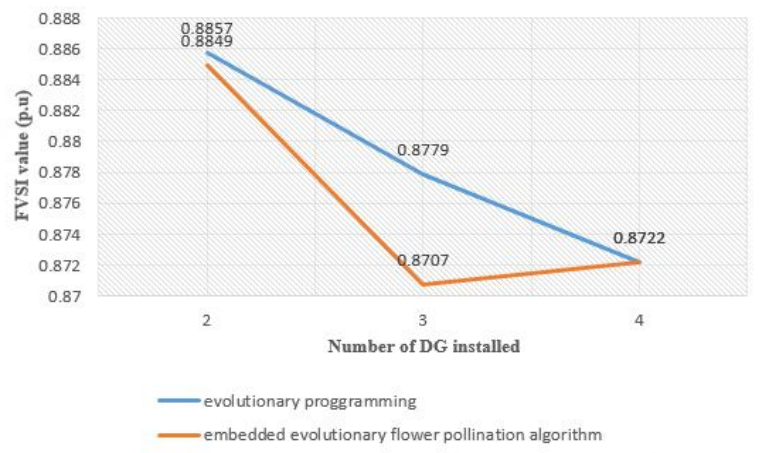

Figure 6: Comparison on the maximum FVSI value between evolutionary programming and embedded evolutionary flower pollination algorithm method

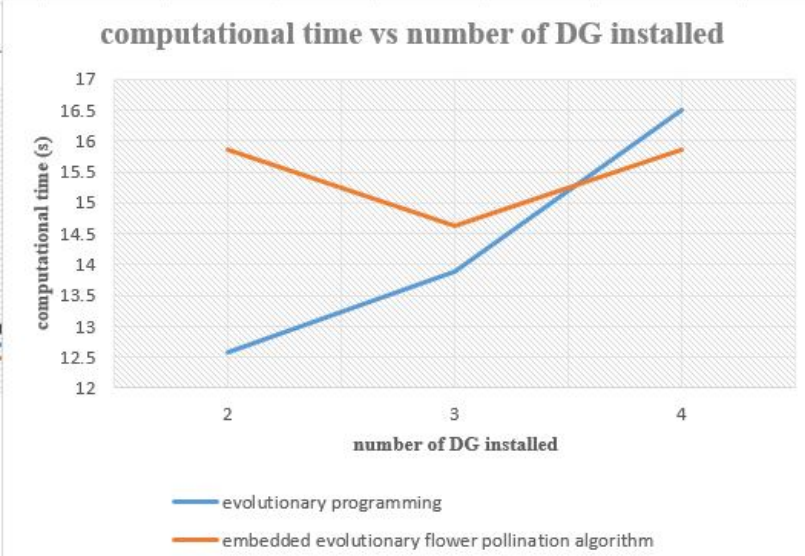

Figure 7 : Comparison on the computational time taken between evolutionary programming and embedded evolutionary flower pollination algorithm method

\section{CONCLUSION}

This paper has presented the embedded flower pollination evolutionary programming-based technique for voltage stability enhancement with distributed generation installation. Comparative studies between the technique Evolutionary Programming and Embedded Flower Pollination Evolutionary Programming were conducted. The computational between the two methods were quite different in term of evaluation and computational performance. The analyzed data show that the embedded flower pollination evolutionary algorithm had better finalized result for the voltage stability index and iteration rate for the system to converge however it is quite unstable as the final output did have slightly difference in value during the first and second time running. In the nutshell this project had shown a successful comparison result between the two-method used in optimizing the voltage stability index by installing distributed generation in the 33 distributed bus system power.

\section{REFERENCES}

1. E.-S. E. El-Araby and N. Yorino, Reactive power reserve management tool for voltage stability enhancement, IET Generation, Transmission \& Distribution, vol. 12, no. 8, pp. 1879-1888, Apr. 2018. https://doi.org/10.1049/iet-gtd.2017.1356

2. M. Sriramulu and M. R. Rahul, Optimal placing and sizing of DG in a distribution system for voltage stability improvement, in 2016 International Conference on Electrical, Electronics, and Optimization Techniques (ICEEOT), Chennai, 2016, pp. 1469-1475. https://doi.org/10.1109/ICEEOT.2016.7754926

3. S. Hadavi, B. Zaker, H. Karami, A. A. Khodadoost Arani, and G. B. Gharehpetian, Optimal placement and sizing of DGs considering static voltage stability, in 2017 Conference on Electrical Power Distribution Networks Conference (EPDC), Semnan, 2017, pp. 1216.

https://doi.org/10.1109/EPDC.2017.8012733

4. N. R. H. Abdullah, I. Musirin, and M. M. Othman, Transmission Loss Minimization and UPFC Installation Cost using Evolutionary Computation for Improvement of Voltage Stability, in Proceedings of the 14th International Middle East Power Systems Conference, Cairo, 2010, pp. 825-830.

5. N. Amjady and M. Hakimi, Dynamic voltage stability constrained congestion management framework for deregulated electricity markets, Energy Conversion and Management, vol. 58, pp. 66-75, Jun. 2012. https://doi.org/10.1016/j.enconman.2012.01.006

6. Z. Abdul Hamid and I. Musirin, Optimal Fuzzy Inference System incorporated with stability index tracing: An application for effective load shedding, Expert Systems with Applications, vol. 41, no. 4, pp. 1095-1103, Mar. 2014.

https://doi.org/10.1016/j.eswa.2013.07.105

7. I. Kumaraswamy, B. VenkataPrasanth, and S. Tarakalyani, Role of Distributed Generation in Voltage Stability Enhancement, International Journal of Current Engineering and Technology, vol. 4, no. 1, pp. 60-64, Feb. 2014.

8. M. A. Saad, H. A. Abd El-Ghany, and A. M. Azmy, Optimal DG deployment to improve voltage stability margin considering load variation, in 2017 Nineteenth International Middle East Power Systems Conference (MEPCON), Cairo, 2017, pp. 765-771.

https://doi.org/10.1109/MEPCON.2017.8301267

9. J. H. H. Tang, A. M. M. Busrah, A. K. M. K. M. Hussin, and M. Z. C. Wanik, Power system study for Distributed Generation interconnection to distribution network- A Malaysian case study, in 2014 IEEE International Conference on Power and Energy (PECon), Kuching, 2014, pp. 377-381.

10. E. S. Oda and A. A. Abdelsalam, Optimal DGs allocation in distribution networks using modified flower pollination algorithm, in 2017 Nineteenth International Middle East Power Systems Conference (MEPCON), Cairo, 2017, pp. 1424-1429.

11. R. Ishak, A. Mohamed, A. N. Abdalla, and M. Z. C. 
Wanik, Optimal DG placement and sizing for voltage stability improvement using Backtracking Search Algorithm, in International Conference on Artificial Intelligence, Energy and Manufacturing Engineering (ICAEME 2014), Kuala Lumpur, 2014, pp. 29-34.

12. A. H. Majeed, Optimal DG location and size for power losses minimization in Al-Najaf distribution network based on Bee Colony Optimization, International Journal of Advanced Trends in Computer Science and Engineering, vol. 6, no. 3, pp. 23-26, 2017. 13. S. V. Reddy and S. Swathi, Optimal allocation and sizing of multiple distributed generation in distribution network by Ant Colony Search algorithm, International Journal of Advanced Trends in Computer Science and Engineering, vol. 3, no. 1, pp. 59-63, 2014.

14. M. Z. Rosselan and S. I. Sulaiman, Assessment of evolutionary programming, firefly algorithm and cuckoo search algorithm in single-objective optimization, in 2016 IEEE Conference on Systems, Process and Control (ICSPC), Bandar Hilir, 2016, pp. 202-206.

https://doi.org/10.1109/SPC.2016.7920730

15. M. Hajebi, A. Tavakoli, and A. Hoorfar, Frequency

Domain Inverse Profiling of Buried Dielectric Elliptical-Cylindrical Objects Using Evolutionary Programming, IEEE Geoscience and Remote Sensing Letters, vol. 15, no. 4, pp. 503-507, Apr. 2018.

https://doi.org/10.1109/LGRS.2017.2788699

16. M. Basu, Fast convergence evolutionary programming for economic dispatch problems, IET Generation, Transmission \& Distribution, vol. 11, no. 16, pp. 4009-4017, Sep. 2017.

https://doi.org/10.1049/iet-gtd.2017.0275

17. M. Abdel-Akher, A. A. Ali, A. M. Eid, and H. ElKishky, Optimal size and location of distributed generation unit for voltage stability enhancement, in 2011 IEEE Energy Conversion Congress and Exposition, Phoenix, AZ, 2011, pp. 104-108.

https://doi.org/10.1109/ECCE.2011.6063755

18. T. Balachander, P. Aruna Jeyanthy, and D. Devaraj, Short term hydro thermal scheduling using flower pollination algorithm, in 2017 IEEE International Conference on Intelligent Techniques in Control, Optimization and Signal Processing (INCOS), Srivilliputhur, 2017, pp. 1-5.

https://doi.org/10.1109/ITCOSP.2017.8303162

19. X.-S. Yang, Flower Pollination Algorithm for Global Optimization, in Unconventional Computation and Natural Computation, Berlin, Heidelberg: Springer Berlin Heidelberg, 2012, pp. 240-249.

https://doi.org/10.1007/978-3-642-32894-7_27

20. K. Sundareswaran, P. Srinivasararao Nayak, P. Sankar, and V. Vignesh Kumar, Inverter Harmonic Elimination through Flower Pollination Enhanced Genetic Algorithm, International Journal of Advanced Trends in Computer Science and Engineering, vol. 3, no. 1, pp. 342-348, 2014.

21. H. M. Dubey, M. Pandit, and B. K. Panigrahi, Hybrid flower pollination algorithm with time-varying fuzzy selection mechanism for wind integrated multiobjective dynamic economic dispatch, Renewable Energy, vol. 83, pp. 188-202, Nov. 2015.

https://doi.org/10.1016/j.renene.2015.04.034

22. O. Abdel-Raouf, M. Abdel-Baset, and I. ElHenawy, A new Hybrid Flower Pollination Algorithm for solving constrained global optimization problems, International Journal of Applied Operational Research, vol. 4, no. 2, pp. 1-13, May 2014.

23. N. Diab and E. El-Sharkawy, Recent Advances in Flower Pollination Algorithm, International Journal of Computer Applications Technology and Research, vol. 5, no. 6, pp. 338-346, 2016.

https://doi.org/10.7753/IJCATR0506.1003 